\title{
Design and Construction of a Reconfigurable Pedestrian Structure
}

\author{
E.J. Hudson ${ }^{1,2}$ (D) P P. Reynolds ${ }^{1,2}$
}

Received: 15 April 2016 / Accepted: 25 July 2016 / Published online: 8 November 2016

(C) The Author(s) 2016. This article is published with open access at Springerlink.com

\begin{abstract}
The field of vibration serviceability of civil structures is becoming an increasingly important research area. There is a need to better understand the dynamics of these structures and how they interact with human occupants in terms of both their sensitivity to vibrations and the ground reaction forces from moving occupants. However, testing real world in-service structures is not always feasible and the resulting access limitations can limit the range of potential experimental investigations. This paper presents the design and construction of a laboratory structure that enables a wide range of experiments to be conducted under closely controlled conditions. The key novelty with this structure is that it can be reconfigured and reassembled to significantly change the modal frequencies, modal masses and mode shapes. In addition, it is shown that active vibration control can be used to control the modal damping ratios and thereby simulate a range of structures from bare steel footbridges to fully-fitted out office floors.
\end{abstract}

Keywords Reconfigurable structure · Human-induced vibrations · Vibration perception - Active vibration control

\section{E.J. Hudson}

e.j.hudson@exeter.ac.uk

P. Reynolds

p.reynolds@exeter.ac.uk

1 College of Engineering, Mathematics \& Physical Sciences, University of Exeter, Exeter, UK

2 Full Scale Dynamics Limited, The Sheffield Bioincubator, 40 Leavygreave Road, Sheffield, S3 7RD, UK

\section{Introduction}

As vibration serviceability increasingly becomes an important, and sometimes governing, factor in the design of new civil structures it also becomes necessary to further understand the complex interactions between human occupants and structural dynamics. Human ground reaction forces, human perception of vibrations and human-structure interaction are all active fields of research that are critical to developing structurally efficient solutions that are acceptable in terms of vibration serviceability. Additionally, further developments in the field of advanced vibration mitigation technologies for human-induced vibrations, such as active, passive, semi-active and hybrid control, are needed to reduce vibrations to acceptable levels in increasingly challenging environments. On site measurements are incredibly valuable for testing and validating developments or theory, but these are not always convenient or feasible so there is a real need for a laboratory test structure that can be reconfigured to represent a range of structures with varying dynamic properties under controlled conditions.

There have been a number of previous laboratory based structures for investigations into vibration serviceability and human-induced vibrations. For example, Reynolds [1] constructed a simply supported post-tensioned concrete slab strip at the University of Sheffield. This $11.2 \mathrm{~m} \times 2.0 \mathrm{~m}$ wide structure was initially used to investigate the effect of raised access flooring on the vibration performance of longspan concrete floors and was later adopted for a range of experiments [2-4]. The test floor at Virginia Tech Structures and Materials Laboratory [5] was a steel-concrete composite structure with overall dimensions of $9.15 \mathrm{~m} \times$ $2.44 \mathrm{~m}$. A $9.2 \mathrm{~m} \times 9.2 \mathrm{~m}$ floor plate was built by Souza 
and Battista (as described by Varela and Battista [6]), and was formed by a reinforced concrete floor deck supported by a steel space truss. Additionally, EMPA [7] constructed a $20 \mathrm{~m} \times 2.5 \mathrm{~m}$ cable stayed bridge using glass-fibre reinforced plastic profiles forming a girder.

There are other similar structures and though they are all highly useful platforms to investigate the dynamics of structures with human occupants and control of vibrations, they are limited in that once constructed their dynamic properties are relatively fixed and can only be changed by the addition of significant mass. More recently, Živanović [8] built a composite steel/concrete footbridge at the University of Warwick with adjustable supports. The overall dimensions of the bridge deck were $19.9 \mathrm{~m} \times 2.0 \mathrm{~m}$ but the movable supports could change the span from $15.0 \mathrm{~m}$ up to $18.7 \mathrm{~m}$, thereby modifying the stiffness and mode shapes which provided scope for a wider range of research experiments.

A logical extension of this concept is to develop a structure with variable ratio of length to width, allowing varying families of mode shapes to be achieved. This would have the benefit of a wider scope of achievable dynamic properties and enable distinct families of modes to be studied, from those in high aspect ratio structures, such as footbridges and walkways, to those with smaller aspect ratios, such as building floor plates.

Hence, this paper presents the development of a novel laboratory-based test structure that can be reconfigured to facilitate significant changes to all key dynamic properties; specifically, the natural frequencies, modal masses, mode shapes and modal damping ratios. The developed structure can represent the dynamics of a range of structures, from pedestrian footbridges to fully fitted out office floors. Active vibration control (AVC) was used to control the level of damping apparent in the structure, enabling a bare steel structure to represent the damping changes brought about by non-structural partitions and similar mechanisms; a feature that enables more realistic representation of real-life civil structures.

The layout of the paper is as follows. First, the key features of the design of the structure are presented in
"Design". This details the initial design choices made and the modelling to ensure the resulting structures had dynamic properties within the frequency and mass ranges of interest. Following from this, the structure was assembled into two of its possible configurations and an experimental modal analysis (EMA) was performed to measure the true, as-built, dynamic properties. This is described in "Experimental Analysis". The use of AVC to control the level of damping in the structure is presented in "Supplementary Damping Using AVC". This describes both the design of the AVC system and the experimental results. Finally, concluding remarks are presented in "Conclusions".

\section{Design}

\section{Initial and Geometric Design}

The structural type chosen for the reconfigurable pedestrian structure was a steel framed structure with SPS plates (Sandwich Plate System, a proprietary system from Intelligent Engineering) supported by steel beams via bolted connections. The SPS plates were a composite material, with a polyurethane elastomer (19mm thick) sandwiched between two steel plates (each $12 \mathrm{~mm}$ thick). This design has advantages over other alternatives, such as precast concrete elements, because it is very simple to disassemble and reassemble in different configurations and it is relatively robust to damage during this reassembly. The thickness of steel and polyurethane layers were chosen so that the self weight of the structure was more representative of that of a full size floor or footbridge and because of this they were much thicker than strength requirements alone would dictate.

It was decided that twelve SPS plates of dimension $2.50 \mathrm{~m} \times 1.25 \mathrm{~m}$ would maximise the number of different structural arrangements possible within the constraints of the size of the laboratory. These would be arranged in one of five possible alternatives: $6 \times 1(15 \mathrm{~m} \times 1.25 \mathrm{~m}), 12 \times$ $1(15 \mathrm{~m} \times 2.5 \mathrm{~m}), 6 \times 2(7.5 \mathrm{~m} \times 5 \mathrm{~m}), 4 \times 3(10 \mathrm{~m} \times$
Fig. 1 Different structural configurations (note the SPS plates shown here do not include any offset)

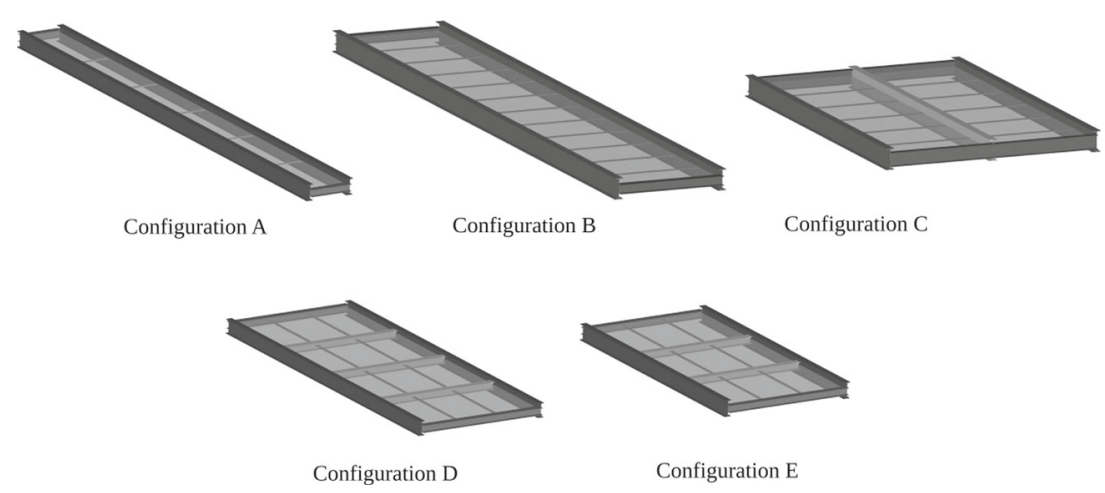


$3.75 \mathrm{~m})$ and $3 \times 3(7.5 \mathrm{~m} \times 3.75 \mathrm{~m})$, as shown in Fig. 1 and denoted by Configurations $\mathrm{A}$ to $\mathrm{E}$.

\section{Superstructure Design}

The steel beams were designed to maximise reusability between different structural arrangements as much as possible to minimize the total number of beams required. However, space limitations with the laboratory area meant that the $15 \mathrm{~m}$ span beams would be too large to store when not in use, so these were designed to be made from two $7.5 \mathrm{~m}$ beams spliced together. This has the benefit that these beams can be re-used in Configurations $\mathrm{C}$ and $\mathrm{E}$ but it does mean that they are oversized in this arrangement as they have capacity to span $15 \mathrm{~m}$.

In addition, splice plates that span between the SPS plates were required and had cross section dimensions $200 \mathrm{~mm}$ $\times 12 \mathrm{~mm}$. The final beam lengths and sizes are shown in Table 1, along with the masses of the steel beams and the SPS plates. From this the total mass of each structural configuration is shown (note that this does not include the small additional mass of the splice plates used to combine two $7.5 \mathrm{~m}$ beams into one $15 \mathrm{~m}$ beams nor the mass of bolts and fixings etc).

\section{Supports Design}

The supports for the structure were reused for all configurations and were constructed from a column section with a stub cantilever (corbel) that could be bolted on at various heights to raise or lower the height of the entire structure above ground level. This facilitated the provision of space underneath the structure for actuators to provide excitation forces through reaction with the laboratory floor surface, if necessary. A levelling system was designed to allow for small adjustments to be made to account for the varying level of the underlying laboratory floor, as shown in Fig. 2. A steel bar was welded to this levelling plate, upon which the lower flange of the steel I beam of the structure rests. This steel bar acted as the only point of contact between the structure itself and the laboratory floor and provided as close to a knife edge support as possible. This modular design for the supports was chosen since the knife-edge support could in future be replaced with spring/bearing supports, to facilitate yet wider range of structural dynamic properties.

The column itself was bolted to a base plate and it was positioned such that the vertical gravity load from the structure acted through the centre of the base plate and hence overturning moments were minimized. Although the base was designed to be stable as a free-standing structure, holding down bolts were provided to the laboratory floor to ensure the structure remained safe in the case of extreme loading. Similarly, the vertical plate at the end of the stub
Table 1 Steel beam and SPS panels lengths and masses for each structural configuration

\begin{tabular}{|c|c|c|c|}
\hline Item Name & Length (m) & Quantity & Mass $(\mathrm{kg})$ \\
\hline \multicolumn{4}{|l|}{ Configuration A } \\
\hline $457 \times 191 \times 82 \mathrm{UB}$ & 7.50 & 4 & 2460 \\
\hline $203 \times 203 \times 46 \mathrm{UC}$ & 1.25 & 2 & 115 \\
\hline $200 \times 12$ Splice Plate & 1.25 & 5 & 117 \\
\hline \multirow[t]{2}{*}{ SPS Panel } & $\mathrm{n} / \mathrm{a}$ & 6 & 4474 \\
\hline & & Total & 7166 \\
\hline \multicolumn{4}{|l|}{ Configuration B } \\
\hline $457 \times 191 \times 82 \mathrm{UB}$ & 7.50 & 4 & 2460 \\
\hline $203 \times 203 \times 46 \mathrm{UC}$ & 2.50 & 2 & 230 \\
\hline $200 \times 12$ Splice Plate & 2.50 & 11 & 517 \\
\hline \multirow[t]{2}{*}{ SPS Panel } & $\mathrm{n} / \mathrm{a}$ & 12 & 8947 \\
\hline & & Total & 12154 \\
\hline \multicolumn{4}{|l|}{ Configuration $\mathrm{C}$} \\
\hline $457 \times 191 \times 82 \mathrm{UB}$ & 7.50 & 2 & 1230 \\
\hline $203 \times 203 \times 60 \mathrm{UC}$ & 7.50 & 1 & 450 \\
\hline $305 \times 165 \times 40 \mathrm{UB}$ & 5.00 & 2 & 400 \\
\hline $200 \times 12$ Splice Plate & 2.50 & 10 & 470 \\
\hline \multirow[t]{2}{*}{ SPS Panel } & $\mathrm{n} / \mathrm{a}$ & 12 & 8947 \\
\hline & & Total & 11497 \\
\hline \multicolumn{4}{|l|}{ Configuration D } \\
\hline $406 \times 178 \times 67 \mathrm{UB}$ & 10.00 & 2 & 1340 \\
\hline $203 \times 203 \times 46 \mathrm{UC}$ & 3.75 & 5 & 863 \\
\hline $200 \times 12$ Splice Plate & 2.50 & 8 & 376 \\
\hline \multirow[t]{2}{*}{ SPS Panel } & $\mathrm{n} / \mathrm{a}$ & 12 & 8947 \\
\hline & & Total & 11526 \\
\hline \multicolumn{4}{|l|}{ Configuration E } \\
\hline $457 \times 191 \times 82 \mathrm{UB}$ & 7.50 & 2 & 1230 \\
\hline $203 \times 203 \times 46 \mathrm{UC}$ & 3.75 & 4 & 690 \\
\hline $200 \times 12$ Splice Plate & 2.50 & 6 & 282 \\
\hline \multirow[t]{2}{*}{ SPS Panel } & $\mathrm{n} / \mathrm{a}$ & 9 & 6710 \\
\hline & & Total & 8912 \\
\hline
\end{tabular}

cantilever prevented the I beam from sliding laterally due to any potential externally applied lateral loads.

These details are illustrated in Fig. 2 which shows two photographs of one of the supports. In addition, a safety handrail with a post at each support was included. This was intentionally attached to the support rather than the test structure itself to minimize interaction effects. Two wires were passed through the top and middle of the posts and tensioned to provide a safety barrier.

\section{Finite Element Modelling}

Finite element (FE) models of the five structural arrangements were created using the commercial FE package ANSYS. The 3D linear beam element, Beam188, was used 
Fig. 2 Support details
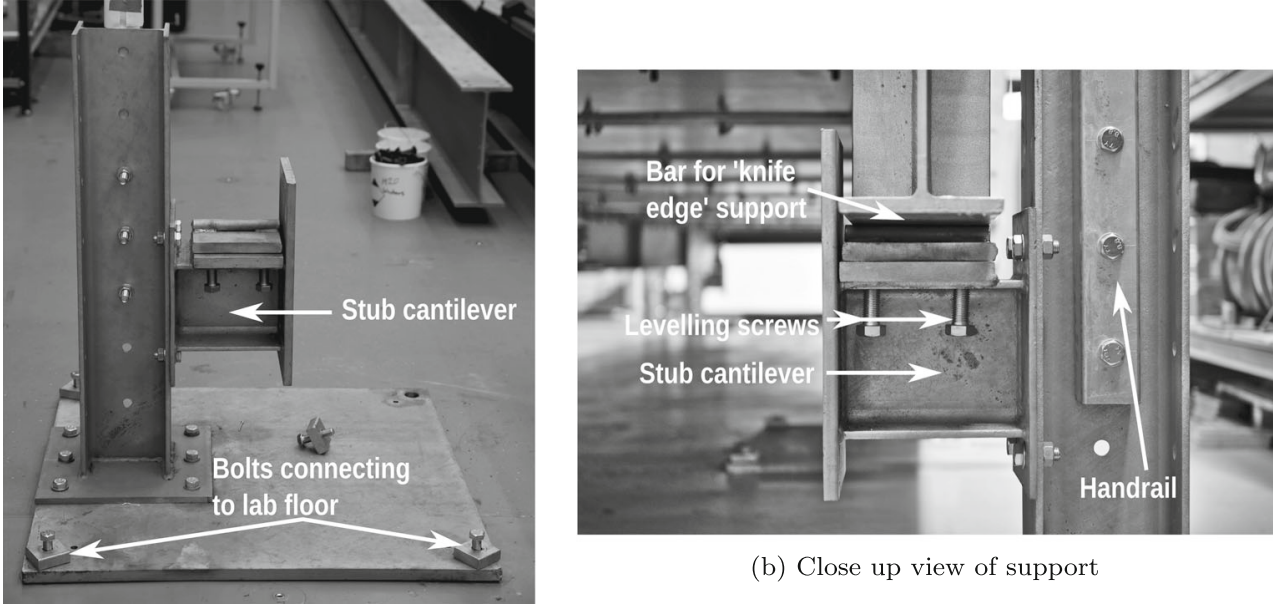

(b) Close up view of support

(a) View of support

to model the structural steel, whilst the elastic shell element with bending and membrane capabilities, Shell63, was used to model the SPS plates. The composite nature of the SPS plates was modelled by calculating an equivalent thickness that provided the same second moment of area of the SPS plate and a density such that the net mass equalled that of the SPS plates.

There was some uncertainty regarding the degree of connectivity that could be achieved between the SPS plates and the structural steelwork, namely with the relatively thin splice plates transferring moment between the SPS plates. Therefore, the degree of composite action was simplified by assuming to vary constantly throughout and was modelled by varying the offset of the beams from the SPS plates from the two extremes of $0 \%$ (no composite action) to $100 \%$ (fully composite action), with the expected value somewhere within this range. A simplification was made in the FE modelling procedure and the supporting cantilever and column was not explicitly modelled. A translational restraint was applied to each corner to replicate the knife edge supports.
A modal analysis was carried out for each structural configuration and for each level of assumed composite action for the SPS plates. The natural frequency and modal masses for the first mode of vibration are shown in Fig. 3. As would be expected, the modal mass predictions remain relatively unchanged by the change in beam offset but there is significant change in natural frequency. In all cases it is seen that this led to the five structural configurations having fundamental natural frequencies varying over a wide range, subsequently allowing for a range of different floor and footbridge scenarios to be replicated effectively in the laboratory environment.

\section{Experimental Analysis}

To date, the structure has been assembled in two of its designed configurations; firstly Configuration $\mathrm{C}$ and then Configuration B. This has facilitated experimental determination of the as-built structural vibration characteristics, which are described here.
Fig. 3 FE model configuration predictions for first mode of vibration for various composite action between SPS plates and steel beams

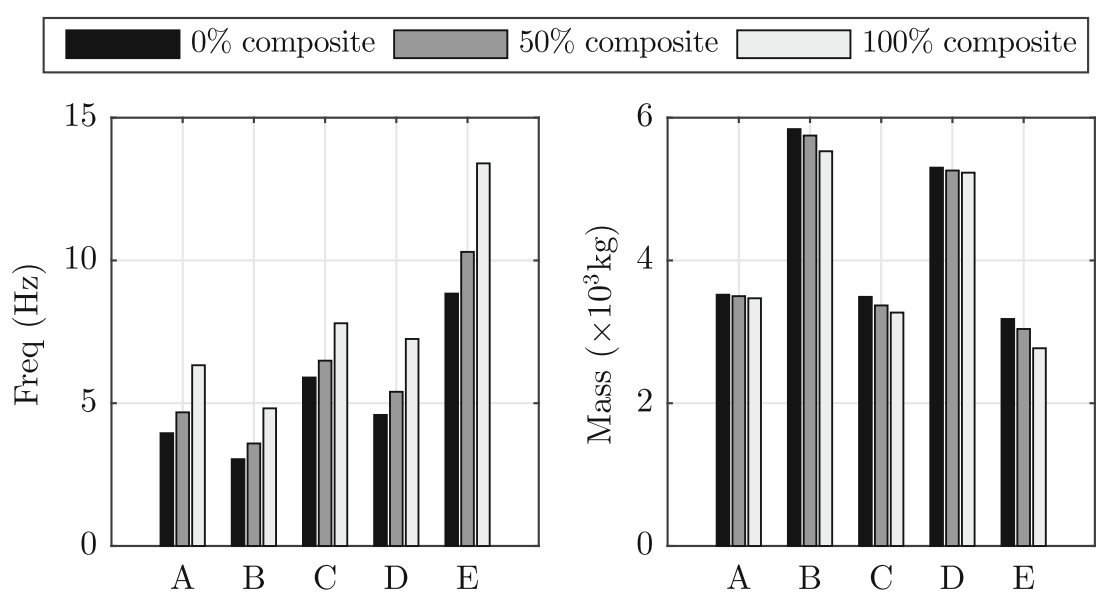


Fig. 4 Photo showing test setup on configuration $\mathrm{C}$

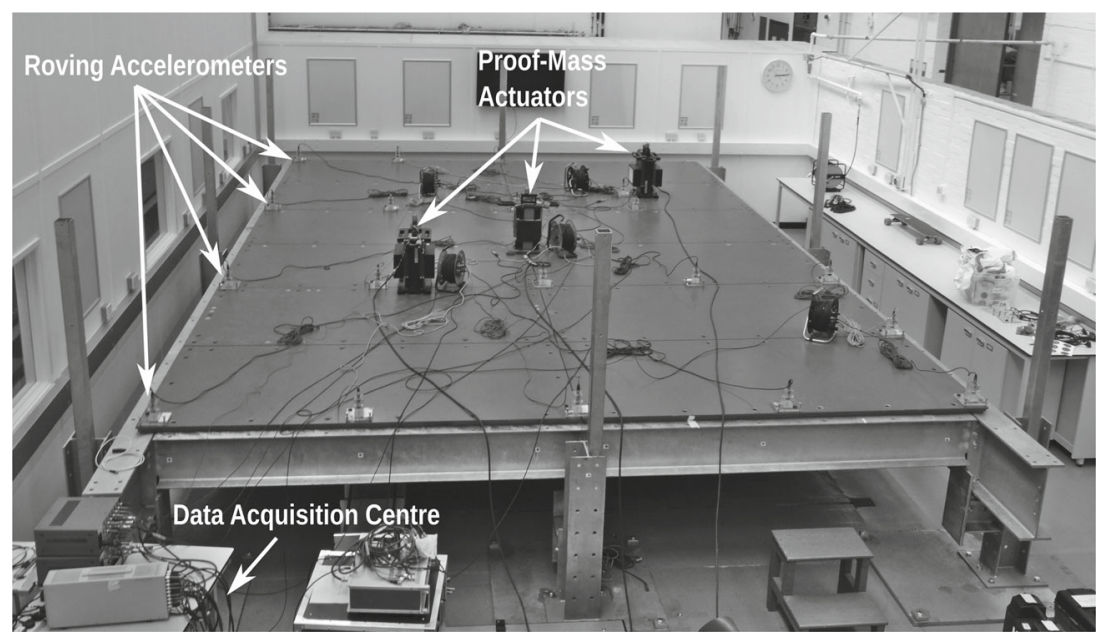

\section{Configuration C}

A photograph of the as-built Configuration $\mathrm{C}$ is shown in Fig. 4. This section describes the EMA that was performed on this configuration to identify the as-built dynamic properties.

\section{Equipment and test grid}

The modal properties of this structure were experimentally determined through forced vibration testing with a set of proof-mass actuators and roving accelerometers. Two APS Dynamics model 400 actuators (with $30 \mathrm{~kg}$ inertial mass) and one APS Dynamics model 113 actuator (with $13 \mathrm{~kg}$ inertial mass), were used to provide the input excitation force. All three actuators were driven simultaneously with uncorrelated random signals in a Multiple Input-Multiple Output (MIMO) configuration. The forces from each of these actuators were measured using Endevco model 77541000 piezoelectric accelerometers attached to the moving armatures; the acceleration measurements being scaled by the moving actuator masses to provide force measurements. The acceleration responses of the structure were measured using a set of Honeywell QA700 and QA750 servo accelerometers. The accelerometers and actuators were set on a test grid as shown in Fig. 5; the location of the actuators was set to maximise the number of modes that could be excited. The drive signals to the actuators and the acceleration measurements were generated and recorded respectively using a Data Physics SignalCalc Mobilyzer spectrum analyser.

\section{Post-processing}

An important initial quality assurance check is the reciprocity check; i.e. for any two locations $\mathrm{A}$ and $\mathrm{B}$, an input
Fig. 5 Test grid with test points (TP) shown

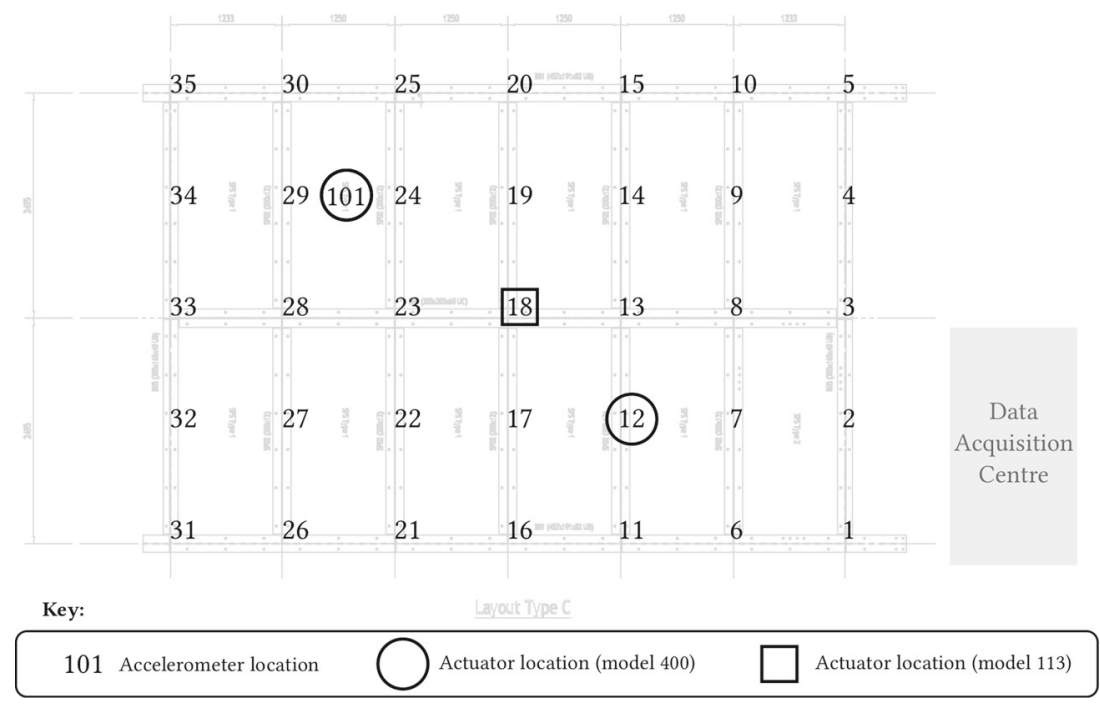


Fig. 6 Reciprocity checks for 3 TPs on structure $\mathrm{C}$
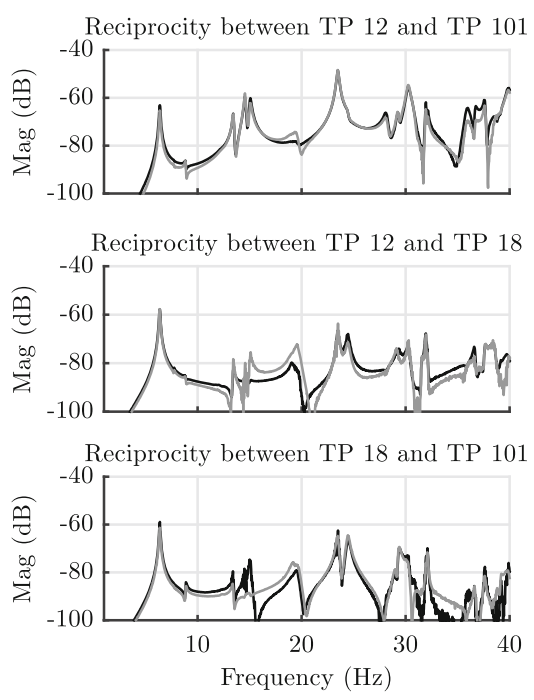

(a) Magnitude
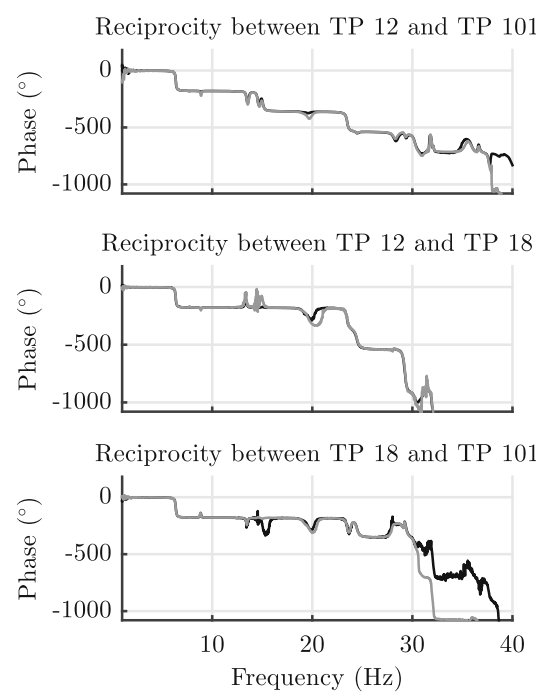

(b) Phase at $\mathrm{A}$ and output at $\mathrm{B}$ results in the same structural response as an identical input at B and output at A. This check was performed at the location of the three actuators because these were the only locations where both input and output information was available. The measured cross-accelerance FRFs for these locations are shown in Fig. 6.

The finite size of the actuator and accelerometer meant that they could not be perfectly collocated so a small degree of variation between the two cross-accelerance FRFs should be expected. This was observed in the crossaccelerance FRFs involving test point 18 - the central point on the structure. The accelerometer was placed precisely on this test point and then the actuator was sited as close as physically possible. However, this difference lead to noticeable changes in both the magnitude and phase of the cross-accelerance FRF around $15 \mathrm{~Hz}$, which was close to the frequency of two modes of vibration each with an antinode at this point. Generally these were very closely matched with the phase only differing at higher frequencies where the generated FRF was noisier and the unwrapping procedure (used to make the phase plots appear clearer) broke down, with shifts of $360^{\circ}$ being introduced.

The FRFs for all test points relative to all three reference actuator locations were curve fitted using the commercial software ME'scope. A complex mode indicator function was used to identify probable mode locations which were then utilised by a global polynomial curve fitting method to identify the modal parameters, resulting in the mode shapes shown in Fig. 7 and the modal frequency, damping and mass values shown in Table 2. Note, that in Fig. 7 the edges of the mesh are shown on the EMA results to highlight the density of the accelerometer grid, however the FE mesh was much denser than the EMA test grid and the element edges obfuscated the images so are not shown.

The EMA mode shapes closely resembled the FE predicted mode shapes, and the frequencies for the case with composite action approximately $50 \%$ actually matched very closely with the measured frequencies. The EMA mode at $15.0 \mathrm{~Hz}$ was notably higher in frequency than the equivalent FE mode at $14.1 \mathrm{~Hz}$ despite their very similar shape. This could be due to the simplification made in the FE model regarding the degree of composite action. It was assumed that a change in the offset of the beams relative to the plates could account for this. However, this would apply uniformly through the structure when in reality the degree of composite action in each direction would likely differ. A more detailed and thorough FE modelling procedure would be required to capture this detail.

There was generally a higher error in estimating modal mass than other modal properties because this is a function of the estimated mode shape squared [9], so with this in mind the FE and EMA modal masses shown in Table 2 are considered to be relatively close and a good match with the exception of the mode observed at $13.4 \mathrm{~Hz}$ (denoted with an asterisk), which had an unrealistically high modal mass. Through further investigation with the actuators configured horizontally (results not shown in full here for brevity) this was identified as being a horizontal sway mode with a torsional component that could therefore be observed by the vertical accelerometers but was not strongly excited. This increased the error in the mode shape estimation and hence modal mass; subsequent tests with a horizontal shaker produced a modal mass of $8.1 \mathrm{t}$ for this mode. Additionally, this mode was not predicted by the FE model because that model 


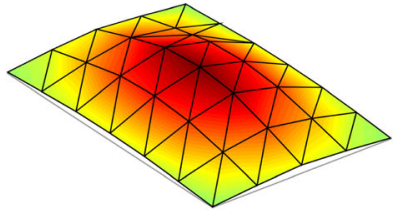

(a) EMA - $6.35 \mathrm{~Hz}$

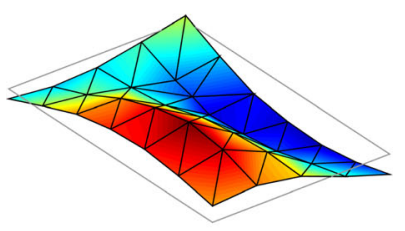

(c) EMA - $13.4 \mathrm{~Hz}$

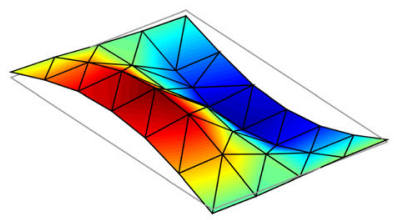

(e) EMA - $14.5 \mathrm{~Hz}$

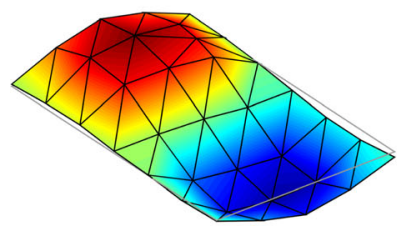

(g) EMA - $15.0 \mathrm{~Hz}$

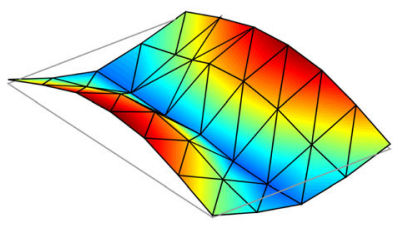

(i) $\mathrm{EMA}-19.6 \mathrm{~Hz}$

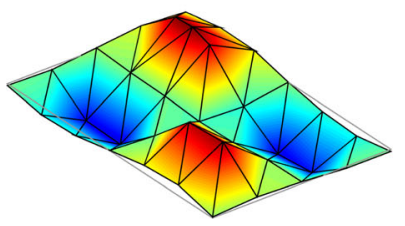

(k) EMA - $23.5 \mathrm{~Hz}$

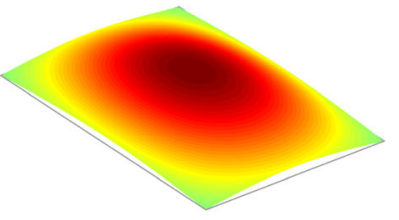

(b) $\mathrm{FE}-6.49 \mathrm{~Hz}$

Mode Not Simulated

(d) $\mathrm{FE}-\mathrm{n} / \mathrm{a}$

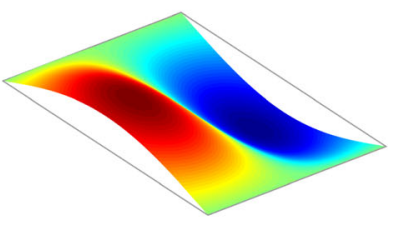

(f) $\mathrm{FE}-14.3 \mathrm{~Hz}$

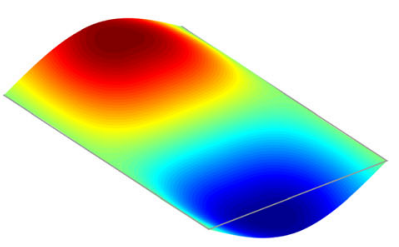

(h) $\mathrm{FE}-14.1 \mathrm{~Hz}$

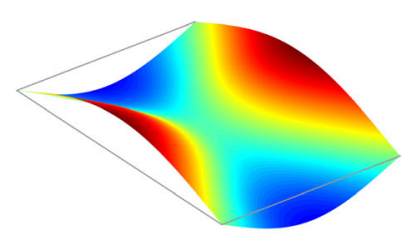

(j) $\mathrm{FE}-20.0 \mathrm{~Hz}$

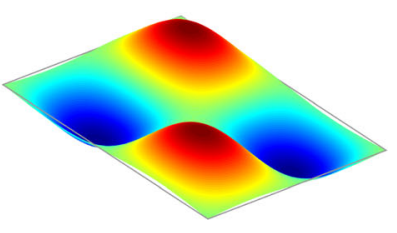

(l) $\mathrm{FE}-25.4 \mathrm{~Hz}$

Fig. 7 Comparison of EMA and FE (50\% beam offset) mode shapes for structure configuration $\mathrm{C}$

Table 2 Comparison between EMA and FE (50\% beam offset) modal properties for structure $\mathrm{C}$

\begin{tabular}{|c|c|c|c|c|c|c|}
\hline \multirow[t]{2}{*}{ Mode Num } & \multicolumn{2}{|c|}{ Freq $(\mathrm{Hz})$} & \multicolumn{2}{|c|}{ Damping (\%) } & \multicolumn{2}{|c|}{ Mass $\left(\times 10^{3} \mathrm{~kg}\right)$} \\
\hline & EMA & $\mathrm{FE}$ & EMA & FE & EMA & $\mathrm{FE}$ \\
\hline 1 & 6.35 & 6.49 & 0.89 & $\mathrm{n} / \mathrm{a}$ & 3.0 & 3.3 \\
\hline 2 & 13.4 & $\mathrm{n} / \mathrm{a}$ & 0.60 & $\mathrm{n} / \mathrm{a}$ & $15.4 *$ & $\mathrm{n} / \mathrm{a}$ \\
\hline 3 & 14.5 & 14.3 & 0.65 & $\mathrm{n} / \mathrm{a}$ & 5.6 & 3.4 \\
\hline 4 & 15.0 & 14.1 & 0.79 & $\mathrm{n} / \mathrm{a}$ & 4.5 & 3.8 \\
\hline 5 & 19.6 & 20.0 & 1.44 & $\mathrm{n} / \mathrm{a}$ & 2.6 & 2.8 \\
\hline 6 & 23.5 & 25.4 & 0.49 & $\mathrm{n} / \mathrm{a}$ & 2.5 & 2.5 \\
\hline
\end{tabular}

did not contain explicit definitions of the column support conditions being engaged by this sway mode.

The modal damping ratios for all modes of vibration were low which was expected for a bare steel structure of this sort. As is shown in Section 2, these damping values were modified in a controlled manner through the use of AVC.

Often structures of this sort are assumed to act linearly with respect to modal properties remaining constant with amplitude of vibration. However, this is not necessarily the case and amplitude can have large effects on the overall structural dynamics. The variation in frequency and damping of the first mode with amplitude of vibration was investigated by performing a shaker shutdown test; i.e. driving the actuator at resonance of the first mode of vibration and then suddenly switching off the excitation. The response of the structure was monitored and the logarithmic decay method was applied repeatedly to the resulting decay curve to calculate the frequency and damping at differing amplitude levels. The results of this are shown in Fig. 8. This shows the damping ratio varied between a maximum of $1.5 \%$ at high amplitudes and a minimum of $1 \%$ at about $6 \times 10^{-2} \mathrm{~m} / \mathrm{s}^{2}$. The frequency showed a degree of amplitude dependence, varying from $6.35 \mathrm{~Hz}$ at low amplitudes to under $6.25 \mathrm{~Hz}$ at high amplitudes, a change of $1.6 \%$. This was similar in magnitude to the amplitude-dependent changes observed on other laboratory structures. For example, the first natural frequency of the concrete slab at the University of Sheffield reduced by $1.5 \%(0.065 \mathrm{~Hz})$ at high amplitudes $\left(1.7 \mathrm{~m} / \mathrm{s}^{2}\right)$ [10] and similarly for the footbridge at the University of Warwick the frequency reduced by $1.2 \%(0.03 \mathrm{~Hz})$ at high amplitudes $\left(1.2 \mathrm{~m} / \mathrm{s}^{2}\right)[8]$.

\section{Human-induced vibration test}

The response of the structure when subject to both walking and jumping at frequencies that result in resonance was investigated. One person walked back and forth between TP 16 and 20 with a step frequency of 127 beats per minute such that the third harmonic of walking matched the first 
Fig. 8 Amplitude dependence of damping ratio and frequency for structure configuration $\mathrm{C}$

Fig. 9 Human-induced structural accelerations on configuration $\mathrm{C}$

Fig. 10 Photos of configuration B

Fig. 11 Test arrangment for EMA of configuration $B$
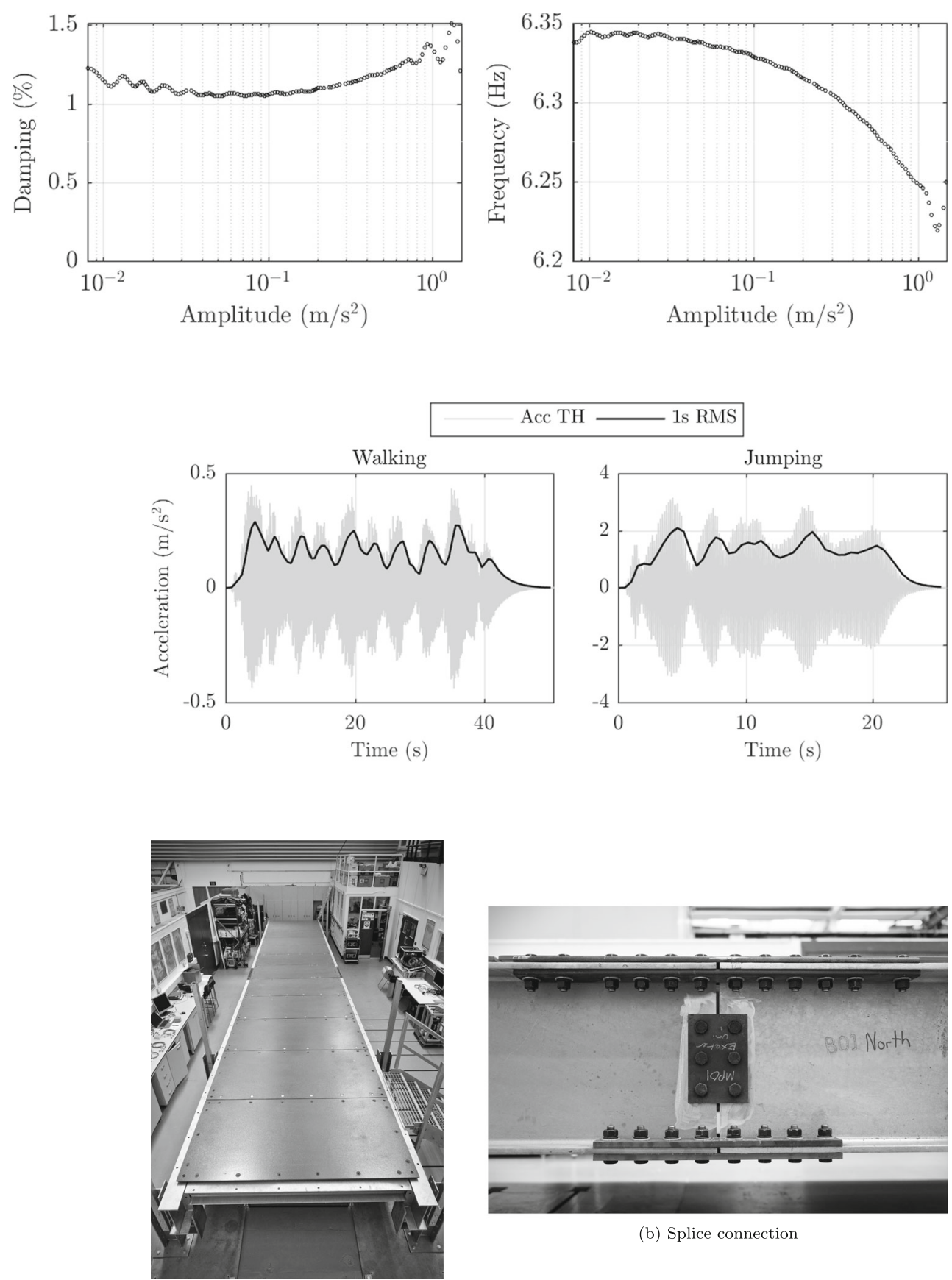

(b) Splice connection

(a) General Arrangement

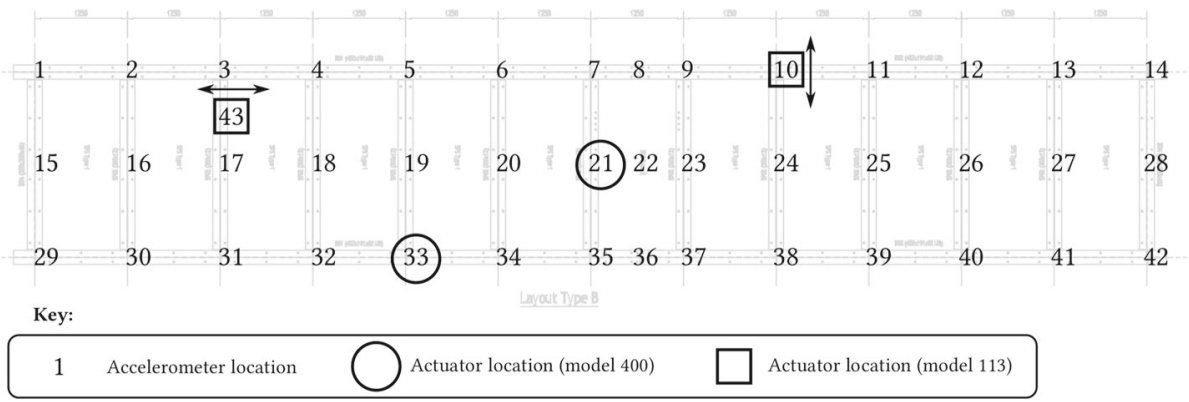


mode of vibration. Another person jumped on the spot at TP 18 at 192 beats per minute such that the second harmonic matched first frequency resonance. In both cases, the structural response was monitored by an accelerometer at TP 13, which was close to the expected location of maximum response but sufficiently far to avoid any risk of damage. The response time histories for both tests are shown in Fig. 9 along with a running one second RMS. It is evident that high responses could be easily achieved through human excitation; though lower responses could be generated by increasing the damping as discussed in "Supplementary Damping Using AVC". These high responses also highlight that the region where amplitude dependent frequency becomes significant could be achieved through human-excitation on this structure.

\section{Configuration B}

Following the previously described tests, the structure was disassembled and reassembled in Configuration B, which was more representative of a footbridge structure and allowed for quite different structural dynamics to be investigated. A photograph of the assembled structure in this configuration is shown in Fig. 10(a) and the detail of the splice connection between the two $7.5 \mathrm{~m}$ beams is shown in Fig. 10(b).

An experimental campaign similar to that described in "Configuration C" was undertaken and hence full details are not repeated here. This structure was considered likely to have significant horizontal motion, therefore a triaxial arrangement of accelerometers and actuators was used, with the test grid shown in Fig. 11.

The results of the experimental analysis are compared with the finite element model with $50 \%$ composite action in Table 3 and Fig. 12. The majority of the mode shapes detected were solely (or predominantly) vertical in nature. However, the modes at $8.42 \mathrm{~Hz}$ and $12.7 \mathrm{~Hz}$

Table 3 Comparison between EMA and FE (50\% beam offset) modal properties for structure B

\begin{tabular}{|c|c|c|c|c|c|c|}
\hline \multirow[t]{2}{*}{ Mode Num } & \multicolumn{2}{|c|}{ Freq $(\mathrm{Hz})$} & \multicolumn{2}{|c|}{ Damping $(\%)$} & \multicolumn{2}{|c|}{$\operatorname{Mass}\left(\times 10^{3} \mathrm{~kg}\right)$} \\
\hline & EMA & $\mathrm{FE}$ & EMA & $\mathrm{FE}$ & EMA & $\mathrm{FE}$ \\
\hline 1 & 3.79 & 3.59 & 0.89 & $\mathrm{n} / \mathrm{a}$ & 6.1 & 5.7 \\
\hline 2 & 5.14 & 6.12 & 0.77 & $\mathrm{n} / \mathrm{a}$ & 6.3 & 2.8 \\
\hline 3 & 8.42 & $\mathrm{n} / \mathrm{a}$ & 0.84 & $\mathrm{n} / \mathrm{a}$ & 9.7 & $\mathrm{n} / \mathrm{a}$ \\
\hline 4 & 12.2 & 12.2 & 0.66 & $\mathrm{n} / \mathrm{a}$ & 2.3 & 4.0 \\
\hline 5 & 12.7 & $\mathrm{n} / \mathrm{a}$ & 0.87 & $\mathrm{n} / \mathrm{a}$ & 4.2 & $\mathrm{n} / \mathrm{a}$ \\
\hline 6 & 18.5 & 19.5 & 0.42 & $\mathrm{n} / \mathrm{a}$ & 2.6 & 2.9 \\
\hline 7 & 20.3 & 20.9 & 0.58 & $\mathrm{n} / \mathrm{a}$ & 3.9 & 3.0 \\
\hline 8 & 22.6 & 24.7 & 0.67 & $\mathrm{n} / \mathrm{a}$ & 1.3 & 2.6 \\
\hline
\end{tabular}

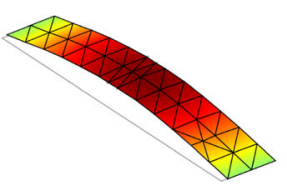

(a) EMA - $3.79 \mathrm{~Hz}$

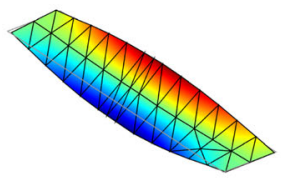

(c) EMA - $5.14 \mathrm{~Hz}$

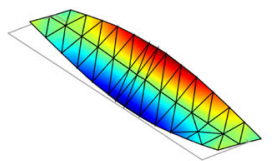

(e) EMA - $8.42 \mathrm{~Hz}$

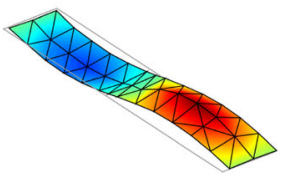

(g) EMA $-12.2 \mathrm{~Hz}$

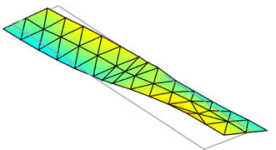

(i) EMA $-12.7 \mathrm{~Hz}$

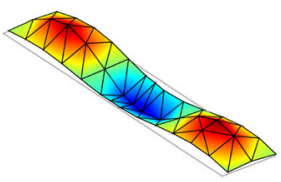

(k) EMA - $18.5 \mathrm{~Hz}$

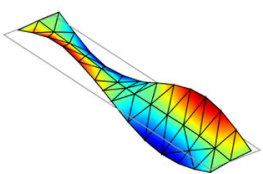

(m) EMA - $20.3 \mathrm{~Hz}$

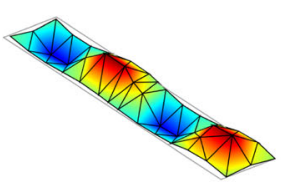

(o) EMA - $22.6 \mathrm{~Hz}$

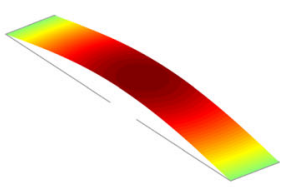

(b) $\mathrm{FE}-3.59 \mathrm{~Hz}$

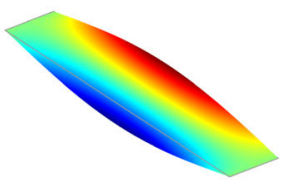

(d) $\mathrm{FE}-6.12 \mathrm{~Hz}$

Mode Not Simulated

(f) $\mathrm{FE}-\mathrm{n} / \mathrm{a}$

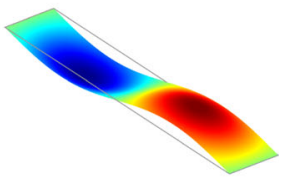

(h) $\mathrm{FE}-12.2 \mathrm{~Hz}$

Mode Not Simulated

(j) $\mathrm{FE}-\mathrm{n} / \mathrm{a}$

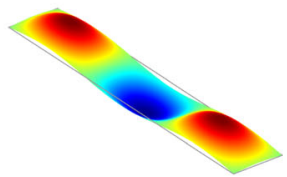

(l) $\mathrm{FE}-19.5 \mathrm{~Hz}$

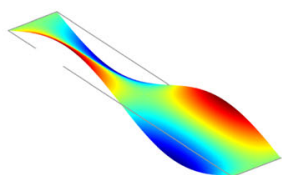

(n) $\mathrm{FE}-20.9 \mathrm{~Hz}$

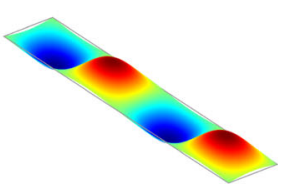

(p) $\mathrm{FE}-24.7 \mathrm{~Hz}$
Fig. 12 Comparison of EMA and FE (50\% beam offset) mode shapes for structure configuration $\mathrm{B}$ 
Fig. 13 Amplitude dependence of damping ratio and frequency for structure B
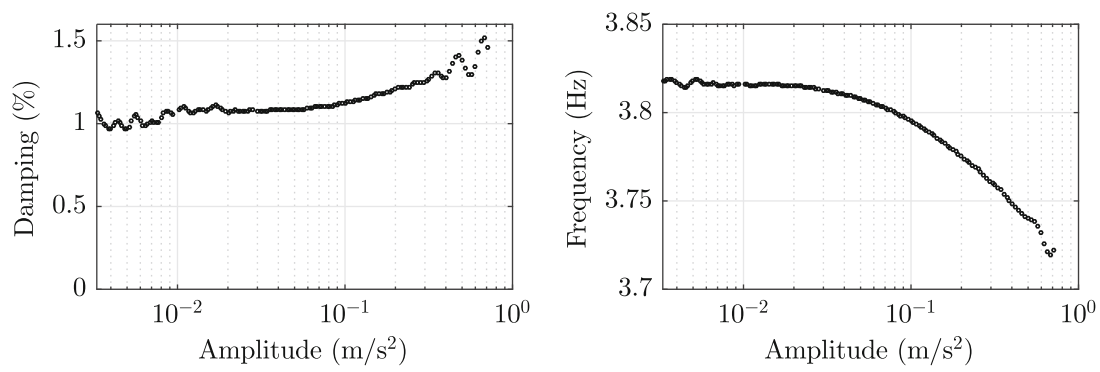

had significant horizontal components. As with Configuration $\mathrm{C}$, these modes were not predicted in the $\mathrm{FE}$ model because the supporting columns were not explicitly modelled.

The amplitude dependence of both frequency and damping of the first mode of vibration was also investigated for Configuration B. A similar shaker shutdown test was performed as per Configuration $\mathrm{C}$, with the results shown in Fig. 13.

A similar pattern was observed with frequency decreasing with amplitude, changing from $3.82 \mathrm{~Hz}$ to $3.72 \mathrm{~Hz}$ at low and high amplitudes respectively. This was a similar magnitude of reduction compared with that measured on Configuration $\mathrm{C}$ though because the fundamental frequency itself was lower this naturally equated to a higher relative change $(2.6 \%)$.

\section{Supplementary Damping Using AVC}

The structure itself has very low inherent damping which is representative of typical steel footbridges. However, floor structures often have internal furnishings which increase the level of damping present. Therefore, to make the structure more representative of a floor structure the modal damping ratios must be increased. AVC has been used in previous research [11-13] to control the level of damping, generally with the aim of increasing this as much as possible to minimize vibration responses due to dynamic pedestrian loading. In this case, AVC was used with carefully chosen feedback gains to introduce relatively small increases in damping, which are representative of the changes introduced through the addition of internal furnishings and non-structural partitions.

\section{Simulations for Design}

Two control locations were chosen, as shown in Fig. 14. One actuator was placed at Loc 1 to control the low frequency modes of vibration (less than $10 \mathrm{~Hz}$ ), whilst the second actuator at Loc 2 was chosen to target higher frequency modes, up to $20 \mathrm{~Hz}$.

In most AVC installations on floors and footbridges there is no surface against which the actuator can react, therefore inertial actuators are required to generate a control force. However, in the current application the laboratory floor itself was utilised and used as a reaction surface with the actuators directly connected to the underside of the structure, as shown in Fig. 15. This has the benefit that the actuators did not take up space on the top surface of the structure, which can then be used unimpeded for whatever experimental test is to be carried out. Additionally, in direct drive mode there were negligible actuator dynamics which in turn simplified the controller design procedure.

A broadband controller, Direct Velocity Feedback (DVF), was chosen so that many modes of vibration could be controlled with the minimum number of actuators. Specifically, the controller consisted of an integrator and feedback gain, a high pass filter to avoid numerical integration issues and a low pass filter to avoid high frequency noise issues. The controller for Loc 1, used to control the low frequency modes of vibration, had a $2^{\text {nd }}$ order high pass filter at $1 \mathrm{~Hz}$ and a $2^{\text {nd }}$ order low pass filter at $30 \mathrm{~Hz}$. The controller for Loc 2 had a high pass filter with cut off frequency at $7 \mathrm{~Hz}$ to reduce control effectiveness for the lower frequency modes. This was needed because a higher feedback gain was required to achieve the same control effectiveness for the higher frequency modes that this controller was targeting [14].

Fig. 14 Actuator locations

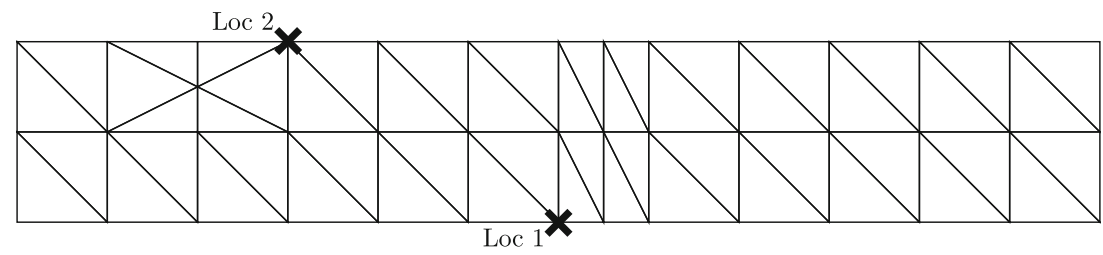




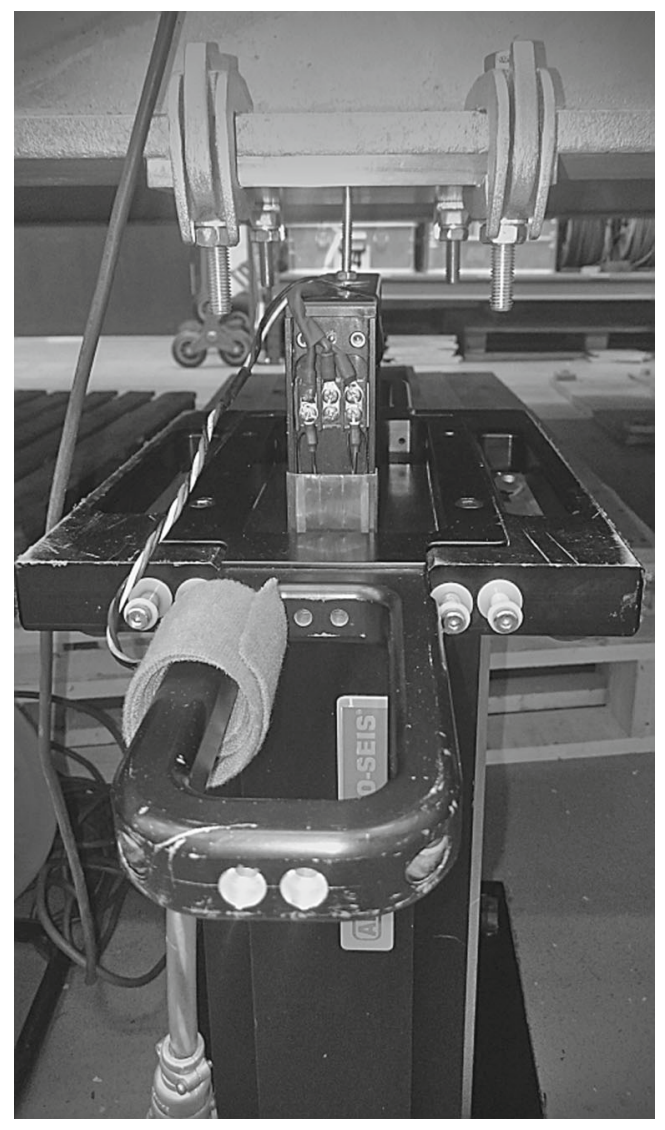

Fig. 15 Actuator directly attached to underside of structure

Two levels of gain were considered to achieve two different levels of damping in the structure. These were gains of $\{10,20\}$ for Loc 1,2 respectively (referred to as $K=1$ ), and gains of $\{20,40\}$ for Loc 1,2 respectively (referred to as $\mathrm{K}=2$ ).

The design of the controller was verified by simulations using measured uncontrolled dynamics at the two chosen control locations. A single actuator (APS Dynamics model 113) was used in inertial mode with two QA750 accelerometers to measure the uncontrolled FRFs at locations 1 and 2, as shown in the left plot of Fig. 16.

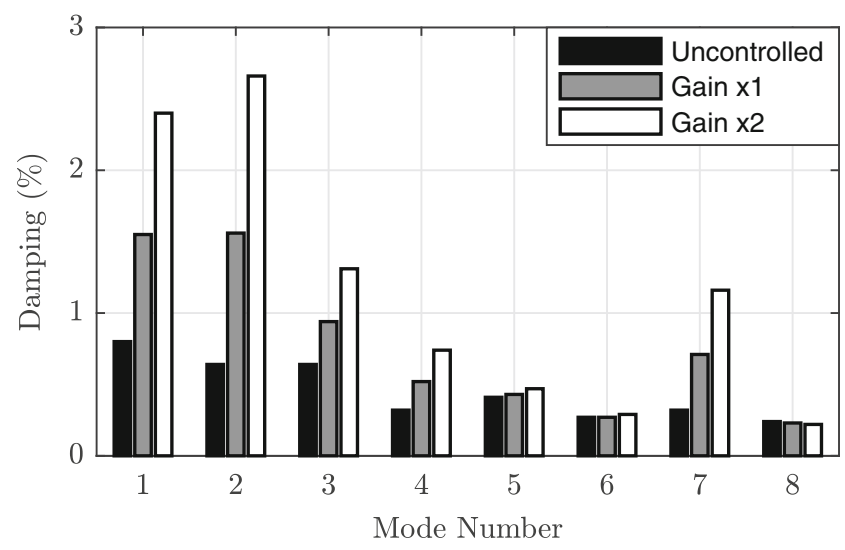

Fig. 17 Experimentally measured varying damping levels

\section{Experimental Results}

Two APS Dynamics model 400 actuators were used for control and hence were connected between the laboratory floor and the underside of the bottom flanges of the two $15.0 \mathrm{~m}$ beams as shown in Fig. 15. Two QA750 accelerometers were collocated these with control actuators.

A National Instruments compactRIO device [15] was used with NI9215 and NI9263 C-Series modules for Analogue Input/Output respectively as the controller for both locations. In addition to the two actuators for control, a single APS Dynamics model 113 actuator was used to excite the structure as an input for the FRF measurements.

The resulting FRFs at Loc 1 are shown in Fig. 16 where a comparison is made with the simulated FRFs. Further to this, these measured FRFs were curve fitted using ME'scope software. The fitted damping values for the first few modes of vibration are compared for the three cases of $K=0$ (uncontrolled), $K=1$, and $K=2$ in Fig. 17. Significant changes in damping were achieved for most modes. Those modes that did not achieve significant increases in damping were modes that had nodal points close to the location of the actuators in this set up and therefore were not expected to achieve much change in damping. A different choice of controller location could have achieved similar changes in damping for these modes if this was desired. Furthermore,
Fig. 16 Controlled FRFs at location 1

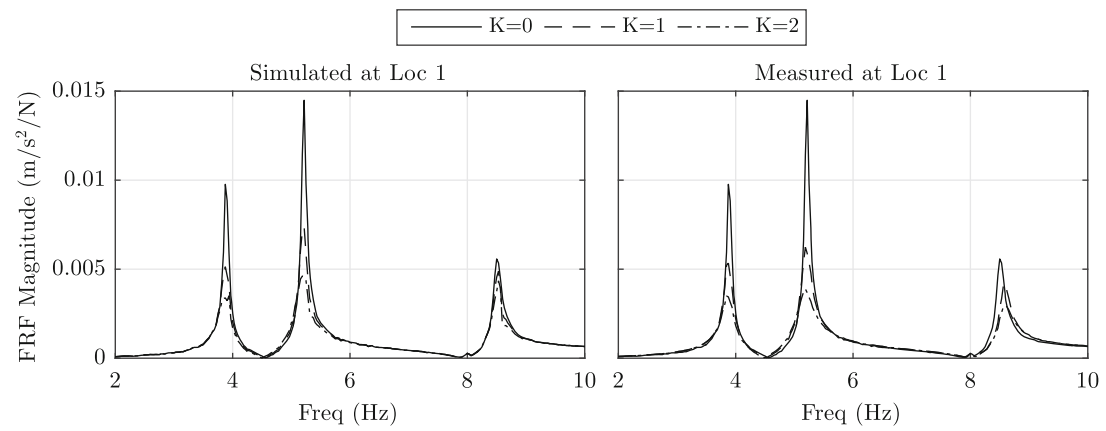


it is possible to increase the feedback gains to much higher levels should even higher damping levels be desired.

\section{Conclusions}

This paper has presented the development of a laboratory structure for testing the interactions between pedestrians and human occupants and structural vibrations. It can also be used for a wider range of vibration serviceability research, such as the development of novel vibration mitigation and isolation technologies. The ability to switch between different configurations of the structure is vital to facilitate study of a wide range of pedestrian structures, and has been achieved through the innovative use of SPS plates with a bespoke set of structural steel beams that can be repeatedly disassembled and reassembled.

A range of dynamics representative of bare steel footbridges through to fully-fitted out office floors can be generated by varying the structural arrangement (to modify the mode shapes, mode frequencies and modal masses) and active vibration control (to modify the modal damping ratios). The use of AVC for precise control of modal damping ratios is a novel feature of this facility, which delivers more precise structural parameters for other vibration serviceability investigations. Future development of the structure will also see the use of spring supports to introduce additional flexibility and hence to extend further the low frequency range of operation of the structure.

The desired performance of this structure has been demonstrated in this paper through a program of assembly, disassembly and reassembly of the structure together with finite element analysis, experimental modal analysis and implementation of supplementary damping using active vibration control.

Acknowledgments The authors would like to acknowledge the financial support given by the UK Engineering and Physical Sciences Research Council via the Responsive Mode Grant (Ref. EP/H009825/1), Platform Grant (Ref. EP/G061130/2) and Leadership Fellowship Grant (Ref. EP/J004081/2).

Open Access This article is distributed under the terms of the Creative Commons Attribution 4.0 International License (http:// creativecommons.org/licenses/by/4.0/), which permits unrestricted use, distribution, and reproduction in any medium, provided you give appropriate credit to the original author(s) and the source, provide a link to the Creative Commons license, and indicate if changes were made.

\section{References}

1. Reynolds P (2000) The effects of raised access flooring on the vibrational performance of long-span concrete floors. $\mathrm{PhD}$ thesis, The University of Sheffield

2. Pavic A, Yu CH, Brownjohn JMW, Reynolds P (2002) Verification of the existence of human-induced horizontal forces due to vertical jumping. In: IMAC XX, (Los Angeles, CA, USA), Society for Experimental Mechanics (SEM)

3. Díaz IM, Reynolds P (2009) Robust saturated control of humaninduced floor vibrations via a proof-mass actuator. Smart Mater Struct 18:125024

4. Díaz IM, Pereira E, Hudson MJ, Reynolds P (2012) Enhancing active vibration control of pedestrian structures using inertial actuators with local feedback control. Eng Struct 41:157166

5. Setareh M, Ritchey JK, Baxter AJ, Murray TM (2006) Pendulum tuned mass dampers for floor vibration control. J Perform Constr Facil 20(1):64-73

6. Varela WD, Battista RC (2011) Control of vibrations induced by people walking on large span composite floor decks. Eng Struct 33:2485-2494

7. EMPA (2003) EMPA Activities 2003: Report on technical and scientific activities, tech. rep., EMPA

8. Żivanovic̀ S., Johnson RP, Dang HV, Dobric J. (2013) Design and Construction of a Very Lively Bridge. In: Proceedings of IMAC XXXI, pp 371-380

9. Ewins DJ (1995) Modal testing: theory and practice. Taunton, Somerset, England: Research Studies Press Ltd. \& John Wiley and Sons Inc.

10. Żivanovic S, Díaz IM, Pavic A (2009) Influence of walking and standing crowds on structural dynamic properties. In: Proceedings of IMAC XXVII

11. Díaz IM, Reynolds P (2010) Acceleration feedback control of human-induced floor vibrations. Eng Struct 32:163-173

12. Hudson EJ (2013) Incorporating active control of human-induced vibrations in floors into buildings. Phd thesis, The University of Sheffield

13. Pereira E, Díaz IM, Hudson EJ, Reynolds P (2014) Optimal control-based methodology for active vibration control of pedestrian structures. Eng Struct 80:153-162

14. Hudson EJ, Reynolds P, Nyawako DS (2016) Fundamental studies of AVC with actuator dynamics. In: Proceedings of IMAC XXXIV (Orlando, FL, USA), Society for Experimental Mechanics (SEM)

15. National Instruments (2011) CompactRIO NI cRIO-9081/9082 Operating Instructions and Specifications, tech. rep. 